\title{
PAYMENT AND SETTLEMENT SYSTEM DEVELOPMENT IN NEPAL: HURDLES AND WAY OUT
}

\author{
Pralhad Giri ${ }^{*}$
}

\begin{abstract}
As stipulated in Nepal Rastra Bank Act, 2002 under article 4 (C), one of the prime objectives of the central bank is to develop a secure, healthy and efficient system of payment, where the function of the same has been given in Article 5 (i) as to establish and promote the system of payment, clearing and settlement and to regulate these activities. Advent of new payment gateway backed by technology has prompted Nepal to develop an efficient national payment system to regulate all the electronic payment mechanism in the country and help integrate small businesses and consumers in the economy. This paper is an attempt of deriving the assessment of payment system of Nepal, with a view to modernize its scope for smooth functioning of financial system. The study suggests that central bank should act on promulgating solid legal and regulatory framework by establishing separate Payment and Settlement Division in order to carry out the function of oversight and operations. It is further recommended to harmonize relations with different government authorities to liberalize infrastructure services; thus ensures smooth execution different payment and settlement services.
\end{abstract}

\section{BACKGROUND}

One of the primarily functions of the financial system is Payment and Settlement System (PSS). It plays pivotal role in effective and efficient circulation that arranges the process of clearing and settlement following a standard set of rules and procedures in an organized manner. It is the medium for the trade and business thus comes as the essential components of circulating money through the usage of monetary policy. Today is the age of globalization and technology. Every single thing is not far and of important value. With advancement of electronic products with high value technology, the role and functionality of payment systems have been changed. Recently, the central bank has succeeded to launch one of the innovative payment system instruments in Nepal. Ultimately, the collective efforts of bankers together with business fraternity have been assured of reforms on payment system development.

Safe, secure and efficient payment system is the goal of every central bank in the globe. Central bank, in one side has the obligation to safeguard the public interest and confidence over money circulation, while it needs to develop the able economic giants to transmit money and financial instruments smoothly and securely through

\footnotetext{
* Asst. Director, Internal Audit Department, Nepal Rastra Bank.Email: pralhad@nrb.org.np, The author would like to thank Mr. Harish Natarajan, Payment System Specialist/WB for his invaluable inputs.
} 
effective use of payment system instruments, on the other. The system must therefore be strong, reliable and credible even in the time of financial crisis.

\section{PSS on TRANSITION}

Central banks have historically influenced payment and settlement systems to provide an array of payment system instruments. As such, central bank provides a safe settlement asset and it may also involve in the transfer of settlement asset. In doing so, it becomes operational stakeholder, so as to formulate basic oversight rules. Oversight is the core function in the process of payment system development. It is the process of monitoring the design, risk management, and operations of system operated by the private sectors. As a matter of fact, through oversight Central Banks seeks to maintain and improve safety and efficiency of systems thus enabling system operators and stakeholders.

In the rapid era of globalization, enhancing efficiency and competition of each financial actor is of great importance. Whether to attract e-commerce and online transaction, development in payment systems and settlement is the central core function of any central bank. Since, Nepal is still crawling in the technology enhancement, technology and its new innovative capability has put forward the important tools to electronic payments and settlement system. At present context where electronic payment system instruments have put forth its leg towards country's demand, the challenges can be outlined in the following areas that focus the attention:

- Need to systematically root the efficient funds transfer mechanism to cover a large network of rural people and their tradition way of entrepreneurship.

- Growing capital \& financial markets need to be given almost all possible instruments of payment system

- Need to build a safe, secure and efficient payment system to cater the needs of country's increasing financial centers.

\section{EXISTING SITUATION}

In Nepal, most account holders have been relying on plastic money especially debit cards to withdraw money instead of waiting in queues to withdraw cash. Moreover, most depositors do not own cheque books in order to avoid additional conditions that come with owning cheque books like extra charges and mandatory balance requirements.

In a dynamic economy, markets need to play a key role in guiding the development of infrastructure, including mechanisms like payments systems. This means that innovation and competition will be central to the future development of the payments system - as they are in other areas of the economy. Strategic planning and investments 
by market participants are shaped by views about the future. To tackle with growing challenges and assessing the need of banking consumer of this modern era, there has been recent development in payment system in Nepal. With traditional conventional banking, recent developed story of payment \& settlement system include cross border payments, domestic payments, payroll management and payment system integration.

Nepal needs to develop an efficient national payment system to regulate all the electronic payment mechanism in the country and help integrate small businesses and consumers in the economy. Unlike various surveys conducted earlier with World Bank assistance, the country is presently in need of efficient payment mechanism like mobile money payment, real time gross settlement system (RTGS) and promulgating a comprehensive legal and regulatory framework for the payment system.

Not surprisingly, a safe, reliable and efficient national payment system will expand access and support economic growth, boosting growth of small and medium enterprises. Strengthening the legal and regulatory framework is therefore, the key medium in order to support introduction and adoption of innovative payment products in both urban and rural markets. Reforms in the payment system would help Nepal attract private investment and bring efficient services to those excluded from the formal banking system.

\section{RECENT DEVELOPMENT ON NEPALESE PAYMENT AND SETTLEMENT SYSTEM}

\section{Strategy and Planning}

In line with the objective that prompt, secure and efficient payment system could help accelerating trade and commerce in Nepal, the central bank is all set to traverse towards efficient e-payment solutions. Stipulated in its Strategic Plan (2012-2016), Nepal Rastra Bank has vowed to study and establish a payment and settlement policy division, feasibility study for the use of Real Time Gross Settlement System (RTGS), formulate Electronic Payment \& Fund Transfer Act and e-payment regulations, validating electronic funds transfer, internet banking, credit card operations, automated SWIFT transactions linking SWIFT and ledger accounts etc. As such, the deadlines and responsible departments at NRB has brought ultimately The South Asia Enterprise Development Facility, managed by IFC of World Bank for the feasibility study of RTGS, Scripless Securities Settlement System (SSSS) along with the national payment gateway. These efforts aim at developing retail payment systems, utilizing technology to expand the reach of financial services, as per stipulated in Strategic Plan (20122016). 


\section{Central Bank's Effort}

As discussed earlier, the need of online payment and quick settlement has prompted Nepal Rastra Bank to start electronic cheque clearing, which significant achievement to indicate that central bank is deeply concerned over the payment \& settlement system development. Therefore, it has licensed Nepal Clearing House Limited (NCHL) for cheque truncation system. With the establishment of NCHL, the manual clearing of cheques of Banks \& FIs through NRB's Clearing House was completely replaced in October 2012.

Electronic Cheque Clearing Sytem (ECC), first effective tool of e-payment system was launched and active since November 2011 together with effort of bankers \& central bank. Softwares were acquired from Progressoft of Jordan. The system designed and installed as NCHL-ECC, which is a national electronic cheques clearing system, that enables clearing of cheques on the same day irrespective of location of the Banks/FIs and their branches.

The committee for payment and settlement systems (CPSS) under Bank for International Settlement (BIS) has clearly mentioned that the role of central bank in payment system development is three fold. It categorizes Central Bank as an operator, a catalyst and a user. Through the operational activities, the central bank should issue cash as a direct payment instrument and deposit claims as the settlement asset for interbank payments. It may also own, operate or participating in the governance of systemically important clearing and settlement systems. The operation role further includes managing settlement accounts and providing settlement credit, both intraday and end-of-day, for participants in the payment settlement system.

As a catalyst, the central bank may contribute to payment system reform and development by initiating, coordinating, researching and consulting on payment system design, operation and policy; and advising, and on occasion even drafting, proposed legislation on the national payment system. The central bank may also play the role of overseer in between and may monitor existing and planned systems and assess them against safety and efficiency objectives; consult, advise and, if necessary, induce change to payment system design and operations; and publish its oversight principles, policies and guidelines. While as a user of payment services in its operational activities, the central bank may participate in clearing and settlement systems in order to use owned and operated by external parties to make and receive payments on its own behalf or on behalf of its customers (such as the government and its agencies). It may also use securities settlement and depository systems for its own operations; and use correspondent banking services for other central banks and financial institutions.

In the changing context, Nepal is coupled with poor infrastructure and inadequate legal and regulatory framework. In a reality, where payment system development is inextricably linked to the development of the bank and non-bank sectors with respect to 
the provision of instruments and services to end users, the harmonization of relations with the banker's association and other key actors is vital. As a matter of fact, banks and their associated institutions are generally the main suppliers of payment accounts, instruments and services to the customers in the end user markets for most countries. In pervasive nature of traditional payment instruments of Nepal, non-bank payment service providers, such as postal payment offices and financial service kiosks in retail organizations, can also provide payment accounts and services to end user markets.

\section{KEY HURDLES}

Despite the sound promise and commitment, the hurdles are on their way to disrupt the ongoing efforts and planning. Financial system in Nepal has been still in the doldrums, due to the lack of visioning the system as a key stakeholder in financial sector reforms and development.

In Nepal, cash dominates almost all spheres of financial activity in the society. This has thus narrowed payment instrument base, whereas cheque is the second widely used non-cash instrument. Until 2011, existing non-cash instruments were not standardized. Still they varied in content, format, physical characteristics and security features, which undermine the introduction of automated processing, and constrain the efficient detection and control of fraud and forgery.

Besides, existing Legal and Regulatory Framework is either outdated, inadequate or does not conform to new payment practices and trends. On the other hand, payment instruments such as ATM, Internet Banking, Electronic Cheque Clearing (ECC) is at very primitive stage that is yet to fetch professional output. ECC has been successfully operating its services in capital Kathmandu and its vicinities, but is still not covered nation-wide. More importantly, the absence of high value clearing such as RTGS for debit instruments, coupled with the absence of instrument value limits and bank exposure caps, increases the risk of interbank exposure.

Recent fraudulent activities including illegal withdrawals through fake ATM cards has made big stumbling block in the plan of payment system development of Nepal Rastra Bank. With the rise in the number of debit/credit card users, fraudsters are increasingly eyeing the plastic money. As of mid-February, there are 3.02 million card users -2.99 million debit cardholders and 33,868 credit card holders. Such incidents call for adoption of better security measures by banks as well as the central bank.

The fraud carried by bank staffs of Himalayan Bank, Nabil Bank has also questioned the respective banks' commitment and determination for effective and sound administration and financial discipline. Likewise, the serious gap in communication and weakness in bank's internal audit and control system has drawn the serious 
attention of bank customers that cripples their 'confidence motion' in somewhat or the other way. The prevalent means of fraud is "phishing", a technique adopted to acquire secret client information by creating a fake website resembling to the bank's original website and communicating with clients and staff.

Because of the increasing level of threats and fear to lose the credibility, by the end of Chaitra 2069, nine commercial banks have slashed the withdrawal limit from ATMs to tackle security threats. They have reduced the withdrawal limit to Rs 10,000 per transaction from ATM consoles. Likewise, cardholders cannot withdraw more than Rs 50,000 on a single day using their ATM cards, while monthly limit has been fixed at Rs 200,000. While discussing with the central bank officials and police investigations are underway, banks that have issued the notice are Nepal Investment Bank (NIBL), Siddhartha Bank, Rastriya Banijya Bank (RBB), Global IME Bank, Sunrise Bank, Machhapuchchhre Bank, Laxmi Bank, Kumari Bank and Citizens Bank International. The move is absolutely a big hurdle to ongoing payment system development effort.

Another part of hurdles in recent payment system is lack of amount limits for certain payment instruments. ECC has been carrying out the net position details every day, but the central bank has failed to reach in the conclusion whether it would give a credit limit to the banks for the final settlement for the possible shortfalls in their balance. This shows cost-effective risk management, and even potentially exposes the clearing house to systemic risk. Another hurdle is narrow shape of institutional framework of payment system. The agencies which relate to the payment system and its development such as credit rating agencies, factors, autonomous clearing house(s) and third party processing organizations to process payments initiated at EFTPOS (Electronic Fund Transfer at Point of Sale) points, do not yet exist. Most of the commercial bank branches are situated in urban areas and district headquarters, leaving the upcountry and rural areas significantly under banked. ${ }^{1}$ Lack of poor infrastructure is another defect on the system. Regional co-operation, which may boost certain risk management measures, payment technologies and electronic processes, and payment system laws, were underestimated and under prioritized. This could have been promoted the interoperability of regional systems so as to laws related to PSS could be harmonized.

Another significant weakness of the present system is lack of using Magnetic Ink Character Recognition (MICR) cheques. MICR cheques are standard cheques that are specially designed and use through Electronic Cheque Clearing System (ECC). ECC in Nepal has already started since November 2011, but MICR cheques which is the keystone to success of ECC, were not still used by a single Bank/FI though MICR cheque specification and its compliance circular has been issued two years ago. It should be therefore, understood as when mechanized processing of cheques using Magnetic Ink Character Recognition (MICR) technology has come into existence, the

1 Asish Kumar Sharma, National Payment Policy in Nepal, Payment Systems in Nepal - Vision 2009-2012 
issuance and compliance of using MICR cheques for the ECC implementation has been significantly underestimated. As such, Electronic Cheque Clearing has shortened the cheque clearing cycle giving entrepreneur a boost, quicker realization of cheques, improved customer service has encouraged payment system. However, full benefits of the technological upgradation in payment and settlement system would be enjoyed when MICR cheques and its compliance is completely followed by bankers and fellow financial companies.

Other blooming area that central bank has not acted despite vowing through its Monetary Policy of 2011-2012, under financial sector reform, regulation and supervision, expansion of facilities and modernization of the payment would be carried out. Paradoxically, it has not addressed what significant contribution was made during the period in its mid-term review. The sluggish pace and development on addressing the issue is important, but cannot be ignored.

\section{DISCUSSION AND RECOMMENDATIONS}

The central monetary authority has to be responsible everywhere in the financial system for the development for the use of money as an effective means of payment. Nepalese financial system has diverse payment systems ranging from paper-based systems where manually payment and settlement related works involved as well as most comprehensive electronic fund transfer system, which are partly secured and partly unsecured transaction on a gross, real time basis. Banks usually cater to both low value retail payments and large value payments relating to the settlement of interbank money market, Government securities and Forex transactions. Through the establishment of NCHL for electronic cheque clearing purpose, most the cheques and drafts are cleared under regular standard session, which may lead to next day for settlement. NCHL-ECC currently supports cheques clearing of four currencies NPR, USD, GBP and EUR with presentment cut-off time at 14:00, paying bank response cut-off time at 15:00 and final settlement at 15:30 for standard (MICR) cheques. And for non-standard (existing non-MICR) cheques, presentment cut-off time is at 12:00, paying bank response cut-off time is at 15:00 and final settlement at 15:30. These timings under different sessions are inadequate to cater the actual need. This should be seen as Cheque clearing Vs Cash payment. Cash withdrawals through cheques usually are closed by 14:30 in Nepal. If a particular bank via electronic cheque clearing by 14:30 does not accept a cheque, it may rush customer to cash withdrawals, which is a significant threat to the plans \& strategy of promoting e-payments in Nepal.

The Global Payment System Survey 2010 by Payment Systems Development Group (PSDG) of World Bank outlined the following sectors for effective payment system development:

i. Legal and Regulatory Framework 

ii. Large-Value Funds Transfer Systems
iii. Retail Payment Systems
iv. Foreign Exchange Settlement Systems
v. Cross-border Payments and International Remittances
vi. Securities Settlement Systems
vii. Payment System Oversight and Cooperation
viii. Planned and On-going Reforms to the National Payments System

Nepal Rastra Bank, by and large to address all the issues mentioned by PSDG, in order to start a full-fledge effective, secure and safe payment \& settlement system.

As stated above in regard to the three fold roles of the central bank, there are four main ways in which a central bank can contribute to the orderly development of the payment system. It can: (i) perform various payment activities and evolve its operating policies to better meet the emerging needs of the system; (ii) be a catalyst for change, drawing on its expertise about the payment system to help formulate realistic development initiatives. $^{2}$ In materializing the objectives stipulated in the central bank's strategy as well as to act on to effective financial sector development, the following strategies need to be incorporated and acted promptly:

a) Modernization of payment system instruments: Direct debit services should be more focused to cater rural people and their initiatives. Moreover, retail payment instruments that of high value through wholesale payment instruments e.g. RTGS, EFT should be introduced so as to effectively serve the personal and retail sectors. Cellular mobile application would be an effective medium for retail payment system. It needs to be a real-time payment switch responsible for processing inter-bank and inter-processor mobile payment transactions. Banking companies and utility companies like Nepal Telecom, NEA, Ncell, KUKL may take in place of regular and periodic credit transfers which is generally denoted by standing orders need to be promoted. Credit instruments, on the other hand need to be promoted to encourage a risk-reduction propensity in the composition of payment instruments. Users need to be sensitized through different mediums clearly distinguishing the existing and new payment instruments. It could further set up standards for the payment instruments for an efficiency enhancement and risk management measurability of payment service markets.

b) Legal \& Regulatory Framework: The major intricacy that financial system facing these days on payment system development is lack of proper legal and regulatory

2 As a part of the recommendation mainly focuses to developing countries, Bank for International Settlement 
framework. Nepal Rastra Bank, in case of Nepalese payment disparities, lacks of its separate division to handle the issues, it too doesn't have befitting by-laws \& directives to curb the fraudulent activities. Existing Banking Offence Act 2007 has outdated or dual meaning to penalize the real culprits, hence needs to be modified. As a matter of fact, strengthening the legal and regulatory framework will facilitate introduction and adoption of innovative payment products in both urban and rural markets. Through the early promulgation of legal \& regulatory framework with the compliance of AML/ CFT, KYC, promoting electronic payment services will result in greater transparency and make it easier for the under-served to carry out transactions. Thus, there should be a panel of experts that needs to be involved in carrying out framework which should consists of payment system development experts, central bankers, representative of prime judiciary institution, bankers, technological connoisseurs etc. The framework must contain settlement finality, legal recognition of netting arrangements, electronic payments, zero-hour rule and similar, competition, consumer protection, enforceability of security interests; SSS: dematerialization/immobilization, settlement finality, novation, lending arrangements; legal basis of the oversight function and overseers; AML/CFT; registration/licensing requirement for non-bank service providers. (PSDG/ WB) Furthermore, Nepal Rastra Bank needs to review and modify its SWIFT timings in co-ordination with the agency and bankers, so as to facilitate basic time to accept large value transfer until the establishment of RTGS.

c) Enhancement of Clearing \& Settlement Systems: Setting different solutions to cover all payments instruments in modernized payments clearing and settlement environment is essential that shall result in many other enhancements on the business processes of clearing and settlement. These include cost reductions, customer satisfaction, and enhanced accuracy business environment. Therefore Automated Clearing House $(\mathrm{ACH})$ is the solution is to facilitate low value bulk volume Direct Credit and Direct Debit transactions amongst banked customers' accounts within the registered clearing member banks being direct, indirect, sub-direct, and technical. With increasing popularity on plastic money in Nepal, Payment Cards Processing System has to be initiated which uses payment cards at points of sale to facilitate authorizations, clearance and settlement. Automated Teller Machine (ATM) Network(s) has to be built facilitate verification, authorization, clearance and settlement among users and their banks or participants. Data and volume of electronic and online has to be recorded since this area is growing. NRB should, through its Payment \& Settlement Division need to closely review, monitor and follow all actors of payment in order to update and develop Online Banking at a time on the ground of prudent and cost-effective. 
d) Management of Payment System Risk: Risk aversion must be initiated under all e-payment solutions. Risk reduction mechanism has to be simultaneously developed along with the policies and legal and regulatory framework so as to control the precipitation of credit, liquidity, settlement, operational, foreign exchange and systemic risks. There also must be standard to measure the perpetuation of fraud, forgery and other fraudulent activities. Risk management measures that could be applied are establishment of dynamic collateral management system to provide liquidity to cover intra-day exposure to liquidity shortages, setting and implementation of multilateral and individual caps with regard to settlement obligations. Similarly, the risk management measures contained in a report entitled Risks Management for Electronic Banking and Electronic Money Activities prepared by the Basle Committee on Banking Supervision, has to be considered for check \& balance of online banking. The BIS Core Principles for Systemically Important Systems (CPSS) has to be observed and adhered to in the operation of netting systems.

e) Developing Payment System Oversight: As a key part of financial system, central bank should have a close interest in system's safe and efficient functioning as this is directly linked to the principal functions of a central bank - safeguarding confidence in the national currency and providing financial stability. Nepal Rastra Bank has been advised to prepare a set of performance benchmark, solid control and mechanism system through PSS supervision modules which need to be applied in the periodic assessment of payment system efficiency and effectiveness. While e-payments are gradually introduced, NRB should act different scopes of oversight including payment instrument and systems, securities settlement systems, third-party service providers and correspondent, banks and custodians. NRB's role at the moment is multi-fold. It should act as payment system operator and participant, a regulator, a catalyst system developer and reformer. These roles are indispensable for the successful implementation of monetary policy, and given their direct relation to payment systems and large volumes of payment transactions arising from trade in securities, NRB should have an intrinsic interest in their safe and efficient functioning. Cashless payment instruments can also be subject to oversight, particularly in view of their importance in the "transaction process" whereby payments are created, validated and transmitted. In the environment of fraud and security issues prevalent, the oversight of payment instruments typically should be referred to the issues concerning instruments that may be relevant to several systems or that are the responsibility of participants in the system. On the other hand, NRB should overview the oversight of payment instruments typically on setting some safety and efficiency standards with their meet.

f) Setting up Institutional Framework: In order to strengthen payment system risk management and enhancing Nepal's financial system, the NRB should promote issuing Credit Reference Bureaus which would assess the risk profiles of some important players in the payment system. NRB therefore should work closely with the stakeholders and other authorities putting a common place for a unique identifier 
for each bank borrowers of Nepal. As a matter of fact, borrower's sound financial discipline needs to be addressed through such bureaus. Moreover, latest electronic payment instruments should be offered through banks in order to extend payment services to the rural areas.

Payment system development is vital for smooth operation of financial system. For successful conduct of strategies stipulated in NRB's Strategic Plan (2012-2016), the NRB should have adequate organizational structure. Especially given the importance of the central bank's role as a payment system operator for ensuring financial stability, $\mathrm{NRB}$ is expected to adequately manage the relationship between the oversight and operations functions. A key element of this is for Nepal Rastra Bank to be transparent about its development as well as oversight of payment systems, including its own, and to apply the same requirements and standards to all of them. It therefore should harmonize relations with different government authorities to liberalize infrastructure services. For example, reduction in duty and charges in application from mobile operator company will ease to automate payment and settlement process. Through the effective use of above recommendations, the nation's financial system will enjoy the effective, safe and reliant payment \& settlement system that can meet the modern business expectations, client's convenience and flexibility contributing towards effective macroeconomic performance and sound financial stability.

\section{Bibliography}

Bank for International Settlement (2001). Core principles for systemically important payment system. Basel, Switzerland. Retrieved from http://www.bis.org/publ/ cpss34e.pdf

Bank for International Settlement (BIS) (2006). General guidance for national payment system development. Basel, Switzerland, retrieved through ISBN 92-9197-702-0 (online)

Committee on Payment and Settlement Systems (1992). Delivery versus payment in securities settlement systems. Basle: Bank for International Settlements, September.

Committee on Payment and Settlement Systems (1996). Settlement risk in foreign exchange transactions. Basle: Bank for International Settlements, March.

ECC Operating Manual (2011). BFIRD, Nepal Rastra Bank

ECC Rule Book (2011). BFIRD, Nepal Rastra Bank

Mishra, B (2008). The development of e-payment and challenges in Nepal. The SEACEN Centre, Retrieved from http://www.seacen.org/GUI/pdf/publications/ research_proj/2008/rp71/Chap6.pdf 
Nepal Rastra Bank (2012). Monetary Policy 2012. Baluwatar, Kathmandu

Nepal Rastra Bank (2012). Strategic Planning (2012-2016). Baluwatar, Kathmandu

Payment System Development Group (2010). Global payment systems survey. World Bank

Payment System Development Group (2010). The global payment system survey. New York: The World Bank. Retrieved from http://siteresources.worldbank.org/ FINANCIALSECTOR/Resources/282044-1260476242691/Zanza_Chimienti_ GlobalPayment_Systems_Survey.pdf

Post Report (2012, Dec.7). Payment system: IFC supporting Nepal. ekantipur.com Retrieved from http://ekantipur.com/2012/12/07/business/payment-system--ifc-supporting-nepal/363751.html

Sharma, A. (2009). National payment policy in Nepal - a concept Paper, submitted to Nepal Rastra Bank, retrieved from http://www.finextra.com/community/fullblog. aspx?blogid=3283 